\section{TCH-023 LIOUID ORAL FORMULATIONS OF PROPRANOLOL HYDROCHLORIDE FOR THE TREATMENT OF INFANTILE HAEMANGIOMAS}

doi:10.1136/ejhpharm-2013-000276.214

IP Horak, 'S Klovrzova, '2J Malis, 'ZZ Sklubalova. 'University Hospital Prague-Motol, Hospital Pharmacy, Praha 5, Czech Republic; 'University Hospital Prague-Motol, Department of Pediatric Hematology and Oncology, Praha 5, Czech Republic; ${ }^{3}$ Charles University Faculty of Pharmacy, Department of Pharmaceutical Technology, Hradec Kralove, Czech Republic

Background Oral propranolol has been found successful in the treatment of infantile haemangiomas. Paediatric dosage forms of propranolol are not commercially available in our country.

Purpose To develop an extemporaneous oral dosage form of propranolol appropriate for children from 14 days to 24 months of age in hospital and an ambulatory care setting and to determinate its stability. The requirement for minimum excipients for the safety of targeted age group was considered.

Materials and Methods A solution of propranolol $2 \mathrm{mg} / \mathrm{ml}$ was prepared from the substance. We used citric acid or citratephosphate buffer to achieve the optimum stability of propranolol ( $\mathrm{pH}$ about 3 ) and simple syrup to mask the bitter taste of the active ingredient. Two formulations (depending on the patient's age) were developed - one using sodium benzoate as preservative and one preservative-free. The preservative-free solution was prepared aseptically with a limited expiry date. The stability of the preserved solution was evaluated for 180 days at room and reduced $\left(2-8^{\circ} \mathrm{C}\right)$ temperatures using a validated HPLC method and $\mathrm{pH}$ measurements.

Results The formulation preserved with sodium benzoate was stable at both temperatures for 180 days. The concentration of propranolol varied between $98.2-102.5 \%$, the $\mathrm{pH}$ value did not change significantly. The efficacy of antimicrobial preservation (Ph.Eur., 5.1.3) was proven for sodium benzoate $0.05 \%$. A risk assessment of the formulation was undertaken $(<100)$ and an appropriate quality assurance system was developed. A glass bottle with an oral syringe enabled the dose of propranolol to be given with flexibility and accuracy.

Conclusions The preparation of propranolol solution in the pharmacy enabled 23 paediatric patients aged 0.6-20.9 months to be treated successfully for haemangiomas by our hospital.

Acknowledgement This work was supported by the Ministry of Health of the Czech Republic as a project of conceptual development of research organisation 00064203 (University Hospital Motol, Prague, Czech Republic)

No conflict of interest.

\section{TCH-024 LONG-TERM STABILITY OF INDOMETHACIN 0.2 MG/ML READY-TO-USE SOLUTION FOR INTRAVENOUS USE}

doi:10.1136/ejhpharm-2013-000276.215

R Moudry, S Hornstein, M Fehr-Bigger, S Guyer. Kantonsspital Graubünden, Institute for Hospital Pharmacy, Chur, Switzerland

Background Indomethacin $1 \mathrm{mg}$ is used in premature infants to close the patent ductus arteriosus. The commercial product Indocid PDA is no longer available in Switzerland. Nevertheless, on our paediatric ward there is a great need for an intravenous indomethacin solution that can be used at a dose of $0.1-0.2 \mathrm{mg} / \mathrm{kg}$ body weight.

Purpose To produce a parenteral ready-to-use solution containing $0.2 \mathrm{mg} / \mathrm{ml}$ indomethacin and to determine the long-term stability using a stability indicating high-pressure liquid chromatography (HPLC) method.
Materials and Methods Liometacen, containing $50 \mathrm{mg}$ sterile indomethacin (as meglumine salt), was reconstituted with $2 \mathrm{ml}$ water for injection and then diluted with $250 \mathrm{ml} \mathrm{NaCl} 0.9 \%$ to a final indomethacin concentration of $0.2 \mathrm{mg} / \mathrm{ml}$. Finally, a $5 \mathrm{ml}$ indomethacin solution was filled into $10 \mathrm{ml}$ sterilised brown glass vials. The entire process took place under aseptic conditions. Sterility testing was performed before final batch release.

The vials were stored for up to 18 months frozen at $-20^{\circ} \mathrm{C}$, at $2-8^{\circ} \mathrm{C}$ or at room temperature, and the solutions were assessed by HPLC for indomethacin and its degradation products.

Results Indomethacin solutions were submitted to conditions of oxidative or heat degradation, and the HPLC method was found to indicate stability.

The stability testing revealed that the solutions retained at least $95 \%$ of their initial indomethacin concentration when they were stored at room temperature for 12 days or at $2-8^{\circ} \mathrm{C}$ for 23 days.

In contrast, when the solutions were stored in a deep-freezer, they were stable for at least 18 months. During this time, no degradation of indomethacin occurred and the indomethacin concentration remained stable.

Conclusions Indomethacin solutions may be prepared in advance and stocked for at least 18 months at $-20^{\circ} \mathrm{C}$. After thawing they can be kept at room temperature for 7 days or alternatively at $2-8^{\circ} \mathrm{C}$ for 14 days. This procedure is used successfully in our hospital for the treatment of the patent ductus arteriosus.

No conflict of interest.

\section{TCH-025 LONG-TERM STUDY OF THE FORMATION OF AGGREGATES IN UNDILUTED BEVACIZUMAB $25 \mathrm{MG} / \mathrm{ML}$}

doi:10.1136/ejhpharm-2013-000276.216

1J Hernández-Jiménez, ${ }^{2} \mathrm{~A}$ Salmerón-García, 'N Navas-Iglesias, 'A Martínez-Ortega, 3J Cabeza-Barrera, 'LF Capitán-Vallvey. 'University of Granada, Analytical Chemistry, Granada, Spain; ${ }^{2 B}$ aza Hospital, Hospital Pharmacy Unit, Baza, Spain; ${ }^{3}$ University Hospital San Cecilio, Hospital Pharmacy Unit, Granada, Spain

Background Bevacizumab, the active substance of Avastin ${ }^{\circledR}$, is a humanised monoclonal antibody that acts as angiogenesis inhibitor, a drug that slows the growth of new blood vessels. It is used to treat several cancers, including colorectal, lung, breast, kidney and ovarian. Bevacizumab binds to vascular endothelial growth factor (VEGF), the key driver of vasculogenesis and angiogenesis, and thereby inhibits the binding of VEGF to its receptors, Flt-1 (VEGFR1) and KDR (VEGFR-2), on the surface of endothelial cells.

Purpose To evaluate the stability of bevacizumab $25 \mathrm{mg} / \mathrm{ml}$ in solution for infusion, in terms of the formation of aggregates once the vial was open. The study was carried out for 15 days since the manufacturer only indicates chemical and physical in-use stability for up to 48 hours at $2^{\circ} \mathrm{C}$ to $30^{\circ} \mathrm{C}$ in sodium chloride $9 \mathrm{mg} / \mathrm{ml}(0.9 \%)$ solution for injection, if the solution was prepared in validated aseptic conditions. The manufacturer also indicates that the prepared solution should not be frozen.

Materials and Methods The study of the formation of the aggregates was carried out by using a size exclusion high performance liquid chromatography method with diode array detection method (SE-HPLC-DAD). Two different storage conditions, i.e. refrigerated at $4^{\circ} \mathrm{C}$ and frozen at $-20^{\circ} \mathrm{C}$ were maintained for 15 days. Samples were characterised by chromatographic analysis immediately after the vial was opened. These chromatographic data were compared with those obtained on subsequent days. A stress study was also conducted.

Results Analysis of freshly-prepared samples enabled us to characterise bevacizumab chromatographically by SE-HPLC-DAD. In the corresponding chromatograms monomers were clearly detected (main peak in the chromatogram) at $7.7 \pm 0.1 \mathrm{~min}$ of retention 
time, as was the presence of possible dimers at $6.0 \pm 0.1 \mathrm{~min}$ (small chromatographic peak). Chromatographic analysis of the same samples stored at room temperature and protected from light in a refrigerator at $4^{\circ} \mathrm{C}$ indicated the absence of a peak at $6.1 \pm 0.1$, the shift of the main peak to $8.1 \pm 0.1$, and the detection of a new chromatographic peak at $9.5 \pm 0.1$.

Conclusions The results of this study indicated the absence of aggregate formation in bevacizumab $5 \mathrm{mg} / \mathrm{ml}$ during the period of monitoring (15 days) under the two storage conditions tested. Nevertheless, they clearly indicate some kind of break down.

Acknowledgement Financial support was provided by the Project PI10/00201 (Instituto Carlos III, Ministerio de Economía y Competitividad, Spain). We also want to thank the Hospital Pharmacy Unit of the University Hospital of San Cecilio which kindly supplied all the bevacizumab samples.

No conflict of interest.

\section{TCH-026 LONG-TERM STUDY OF THE FORMATION OF AGGREGATES IN UNDILUTED CETUXIMAB $5 \mathrm{mg} / \mathrm{ml}$}

doi:10.1136/ejhpharm-2013-000276.217

'A Martínez-Ortega, ${ }^{2}$ A Salmerón-García, 'N Navas-Iglesias, 'J Hernández-Jiménez, 3J Cabeza-Barrera, 'LF Capitán-Vallvey. 'University of Granada, Analytical Chemistry, Granada, Spain; 'Baza Hospital, Hospital Pharmacy Unit, Baza, Spain; ${ }^{3}$ University Hospital San Cecilio, Hospital Pharmacy Unit, Granada, Spain

Background Cetuximab (Erbitux) is a chimeric monoclonal IgG1 antibody, an epidermal growth factor receptor (EGFR) inhibitor, given by intravenous infusion for the treatment of metastatic colorectal cancer and head and neck cancer. Cetuximab is produced in a mammalian cell line (Sp2/0) by recombinant DNA technology. Purpose To evaluate the stability of this therapeutic monoclonal antibody, i.e. cetuximab $5 \mathrm{mg} / \mathrm{ml}$ in solution for infusion, in terms of the formation of aggregates once the vial was open. The study was carried out for up to 15 days since the manufacturer only indicates chemical and physical in-use stability for up to 48 hours at $25^{\circ} \mathrm{C}$, if the solution was prepared in validated aseptic conditions.

Materials and Methods The study of the formation of the aggregates was carried out by using a size exclusion high performance liquid chromatography method with a diode array detection method (SE-HPLC-DAD. Two different storage conditions, i.e. refrigerated at $4^{\circ} \mathrm{C}$ and frozen at $-20^{\circ} \mathrm{C}$, were considered up to 15 days. Samples were characterised by chromatographic analysis immediately after the vial was opened. These chromatographic data were compared with those obtained on subsequent days. A stress study was also conducted

Results Analysis of freshly-prepared samples enabled us to characterise cetuximab chromatographically by SE-HPLC-DAD. In the corresponding chromatograms monomers were clearly detected (peak at $6.77 \pm 0.05$ minutes of retention time) while dimers or aggregates (peaks at retention times near to 6 minutes or smaller) were absent. Chromatographic analysis of the same samples stored at room temperature and protected from light in a refrigerator at $4^{\circ} \mathrm{C}$ and frozen at $-20^{\circ} \mathrm{C}$ over a 15 -day period indicate the absence of any kind of aggregates.

Conclusions The results of this study indicated the absence of the aggregate formation in cetuximab $5 \mathrm{mg} / \mathrm{ml}$ during the period of monitoring (15 days) under the two storage conditions tested.

Acknowledgment This work was supported by funds received by the Project PI10/00201 (Instituto de Salud Carlos III, Ministerio de Ciencia e Innovacion, Spain). We also thank the Pharmacy Unit of the University Hospital San Cecilio which kindly supplied all the cetuximab samples studied.

No conflict of interest.

\section{TCH-027 MEDIA FILL TO VALIDATE THE ASEPTIC PREPARATION OF SODIUM BICARBONATE INTRAVENOUS INFUSION}

doi:10.1136/ejhpharm-2013-000276.218

'E Naidovska, ${ }^{2} \mathrm{~J}$ Bajraktar, ${ }^{3} \mathrm{~B}$ Lazarova. ${ }^{\prime}$ Clinical Hospital, Department for Compounding Sterile products, Bitola, FYROM; 'Institute for Hemodialysis, Hospital pharmacy, Struga, FYROM; ${ }^{3}$ Clinical Hospital, Hospital pharmacy, Stip, FYROM

Background Sodium Bicarbonate is an alkaline agent and is indicated for treating acute or chronic metabolic acidosis. The substance is unstable and when heated in solution it gradually changes into sodium carbonate. That's why we prepared Sodium Bicarbonate Intravenous Infusion aseptically, according to the Standard Operating Procedure.

Purpose To validate the performance of aseptic processes used to produce our sterile product and to meet Good Manufacture Practice Requirements, i.e. to comply with the 'low', twice per year we are performing media fill (process simulation studies).

Materials and Methods Media fills are simulating the whole process in order to evaluate the sterility confidence of the process. Process simulations includes formulation (compounding), filtration and filling. Important factors in the process are: personnel (number, shift changes, fatigue), sterility test for the sterilised components (bottles, stoppers), filled volume per container (sufficient to wet all surfaces of the containers), frequency, media fill sizes, acceptance criteria, environmental monitoring. We select the growth medium and prepared the bulk media as the same process as routine production including filtering process and number of units (the batches is smaller than 1000). Than all units were incubated at $20-25^{\circ} \mathrm{C}$ for 14 days.

Results After the incubation period of the media filled containers they were visually examined for microbial growth. The contamination rate is zero, so, the accepted contamination rate is less then $0,1 \%$. (Contamination rate $=$ Upper confidence limit/Number of filled units $\times 100$ )

Conclusions With media fill we evaluate the aseptic assembly and operation of the sterile equipment, qualified the operators, and assess our technique, and demonstrate that the environmental controls are adequate to meet the basic requirements necessary to produce Sodium Bicarbonate Intravenous Infusion by aseptic procesing.

No conflict of interest.

\section{TCH-028 NEW BULSULFAN PROCEDURE TO IMPROVE BOTH PREPARATION AND ADMIINISTRATION}

doi:10.1136/ejhpharm-2013-000276.219

'B Dekyndt, ${ }^{2} \mathrm{~N}$ Simon, 'M Vasseur, ' ${ }^{1}$ Guerriero, ${ }^{1} \mathrm{O}$ Anzie, ${ }^{3 B}$ Décaudin, ${ }^{4} \mathrm{P}$ Odou. ${ }^{1} \mathrm{C} h r u$ De Lille, Hospital Pharmacy, Lille, France; ${ }^{2}$ Centre Oscar Lambret, Hospital Pharmacy, Lille, France; ${ }^{3}$ University Lille Nord de France, Pharmacy, Lille, France; ${ }^{4}$ UDSL EA GRIIIOT, UFR Pharmacie, Lille, France

Background When pharmacy staff is not available, nurses used to prepare diluted busulfan solution from commercial vials just before administration because of its low stability. Doing this without protection may cause occupational exposure to this cytotoxic drug.

Purpose To devise a new protocol and perform a preliminary evaluation.

Materials and Methods Literature and technical studies were performed to choose the best devices. Nurses and physicians performed a clinical evaluation using a 5-item satisfaction form.

Results Medical devices containing polycarbonate must be avoided because of the interaction with $\mathrm{N}, \mathrm{N}$-dimethylacetamide used as an excipient. The new protocol consists of an individual kit with the commercial solution packed in a syringe, an infusion bag with the 